\title{
John Cunningham Virus T-Antigen Expression on Mild and Severe Dysplasia Adenomatous Polyp, Low and High Grade Adenocarcinoma of The Colon
}

\author{
Dyonesia Ary Harjanti ${ }^{1}$, Cyprianus Murtono ${ }^{1}$, Kidyarto Suryawinata ${ }^{1}$, Angelina Halim², \\ Michelle Felicia Wiryokusuma ${ }^{2}$, Timotius Benedict Djitro ${ }^{3}$ \\ ${ }^{1}$ Anatomical Pathology Department, School of Medicine and Health Sciences, Atma Jaya Catholic University, Jakarta, Indonesia \\ ${ }^{2}$ Medical Program, School of Medicine and Health Sciences, Atma Jaya Catholic University, Jakarta, Indonesia \\ ${ }^{3}$ Internship Program of Anatomical Pathology Department, School of Medicine and Health Sciences, Atma Jaya Catholic \\ University, Jakarta, Indonesia
}

Background: John Cunningham Virus (JCV) was involved in pre-malignant lessions and carcinogenesis of the colon. The purpose of this study was to detect and analyze JCV T-Ag expression in mild and severe dysplasia adenomatous polyp as well as low and high grade adenocarcinoma of the colon.

Materials and Methods: This study used analytic descriptive, cross sectional approach. The samples' paraffin blocks were taken from colon adenomatous polyp cases (all grades of dysplasia) and cases of colon adenocarcinoma (all degrees) at Anatomical Pathology Laboratory, School of Medicine, Atma Jaya Catholic University of Indonesia from 2010-2014 (5 years period). Samples were reviewed from HE slides to determine histopathologic diagnosis, grades of dysplasia and grading. We performed immunohistochemistry staining with monoclonal antibody anti-SV 40-T-Ag to detect JCV T-Ag expression.

Results: We found 7 cases of colon adenomatous polyp, of which 4 (57\%) were mild dysplasia and 3 (43\%) were severe dysplasia. Positive expression of JCV T-Ag was detected in 1 (14\%) mild dysplasia case. Data analysis using Fischer's Exact Test was $p>0.05$. We also found 16 cases of colon adenocarcinoma. 14 cases (87.5\%) of low grade variant and 2 cases (12.5\%) of high grade variant. Positive expression of JCV T-Ag was detected in 2 (12.5\%) low grade cases. Data analysis using Fischer's Exact Test was $p>0.05$.

Conclusion: There was no difference of JCV T-Ag expression in colon adenomatous polyp (mild-severe dysplasia) and colon adenocarcinoma (low-high grade) cases at Anatomical Pathology Laboratory School of Medicine, Atma Jaya Catholic University of Indonesia 2010-2014.

Keywords: colon adenomatous polyp, adenocarcinoma, JCV T-Ag

Date of submission: July 12, 2018

Last Revised: August 17, 2018

Accepted for publication: August 20, 2018

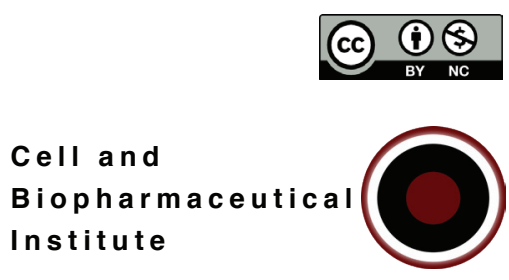

Corresponding Author:

Dyonesia Ary Harjanti

Anatomical Pathology Department

Faculty of Medicine, Atma Jaya Catholic University

Jl. Pluit Raya No.2, Jakarta, Indonesia

E-mail: dyonesiary@gmail.com

Cell and

Institute 


\section{Introduction}

Colon adenomatous polyp otherwise known as colonic adenomas, are commonly encountered benign neoplasms or premalignant lesions; it has a typical feature of glandular epithelial dysplasia. ${ }^{1}$ Colon adenomatous polyp may develop into a malignant neoplastic lesion, colon adenocarcinoma, which is the most common colorectal malignancy. Colorectal cancer occupies the $3^{\text {rd }}$ and $4^{\text {th }}$ place in the world for incidence and leading cause of death respectively. As for Indonesia, colorectal cancer is ranked $2^{\text {nd }}$ after lung cancer in men and ranked $3^{\text {rd }}$ after breast and cervical cancer in women. ${ }^{2}$

Polyps may be prominent in the colonic mucosa (stemmed or sessile) with dysplasia of epithelial or glandular cells. Dysplasia lesions in colon adenomatous polyps can be divided into 2 categories: which is mild dysplasia and severe dysplasia. Colon adenocarcinoma is a malignant neoplastic lesion originating from mucosal epithelial cells or colonic glands. It can also be divided into 2 categories according to the grading of dysplasia, which is low grade (good to moderate differentiation) or high grade (poor to undifferentiated). ${ }^{1}$

Risk factors for these conditions include genetics, age, lifestyle and autoimmune diseases such as inflammatory bowel disease (IBD). Another risk factor that has come to light is from infectious agents. Infectious agents such as John Cunningham virus (JCV) also play a role in the process of neoplasm to carcinogenesis in the colon. ${ }^{3} \mathrm{JCV}$ can be found anywhere around the world and is an oncogenic virus belonging to the family of polyomaviridae virus. This family of virus has a characteristic circular shaped, double stranded DNA and is unenveloped. ${ }^{4}$ The JCV genome consists of 3 parts, the early region, late region and noncoding region. Early region's function is to encode nonstructural proteins such as $\mathrm{T}-\mathrm{Ag}$ and $\mathrm{t}-\mathrm{Ag}$, while the late region serves to encode viral capsid proteins (VP1, VP2 and VP3). The noncoding region contains the origin of DNA replication and serves to regulate the early and late gene. ${ }^{5}$ The JCV is not the cause of colorectal neoplasms, but it is one of the relevant risk factor that can facilitate the progression and development of one or more tumors in humans ${ }^{6}$ such as brain tumors, esophageal cancer and also colorectal tumors.

Nearly $80 \%$ of the human population is susceptible to JCV infections and about $80 \%$ of adults have specific antibodies against $\mathrm{JCV}$, as a sign of a history of being infected with the virus. JCV infections generally occurs during childhood as an asymptomatic and latent infection. ${ }^{7,8}$ Transmission from human to human is not yet known, but JCV can be found in human waste residues indicating the possibility of fecal-oral transmission. In addition, JCV can infect through the respiratory pathway. This is confirmed by the discovery of JCV on tonsils which will then replicate in the lymphoid and latent cells in the kidneys. The latent JCV will be reactivated if the immune system is weakened (i.e., in leukemia, lymphoma or immunosuppressive drug). ${ }^{7-9}$ The activated JCV will take 2 different pathways depending on the infected cells (permissive or non-permissive cells). If permissive cell is infected, the cell will facilitate the virus' DNA replication, then the viruses will be released through the lytic pathway, and the resulting disease is called Progressive Multifocal Leukoencephalopathy (PML). Whereas if non-permissive cells are infected, these cells won't facilitate the virus' DNA replication. The virus will then enter abortive phase or will lead to oncogenesis. ${ }^{7,10}$

$\mathrm{T}-\mathrm{Ag}$ protein is thought to play an important role in the occurrence of neoplasms of carcinogenesis such as transforming premalignant neoplastic lesions into colorectal cancer. This is presumed due to expression of T-Ag would result in inactivation of tumor suppressor genes such as $\mathrm{p} 53, \mathrm{pRb}$ and APC/ $\beta$-catenin which play a role in DNA repair. ${ }^{11}$ The JCV T-Ag expression will bind, inactivate p533 and interfere with p21WAF-1 regulation. This leads to damaged DNA going forward to the next phase without any inhibition from p53 and p21, resulting in uncontrolled cell proliferation. ${ }^{12}$ Disrupted p21 regulation will cause $\mathrm{pRB}$ phosphorylation by cyclin-cdk and release E2F. In addition, E2F free from $\mathrm{pRb}-\mathrm{E} 2 \mathrm{~F}$ bond is also caused by the interaction of T-Ag and pRB. Free E2F will enter into the nucleus and cause cells to continue proliferating. ${ }^{13,14}$ $\mathrm{T}$-Ag will bind free $\beta$-catenin; increase the stability of $\beta$-catenin and accelerate induction of cell proliferation. The $\beta$-catenin mutation will also stimulate cell proliferation genes. ${ }^{15}$

Several previous studies on the potential roles of JCV in the occurrence of colorectal cancer has been done, but there has been no such research in Indonesia. Some of these studies takes place in Japan ${ }^{10}$, Jordan ${ }^{7}$, China ${ }^{4}$ and Taiwan ${ }^{16}$. This is the basis of our interest to analyze and detect the presence of T-Ag protein from JCV on the tissue biopsy/ colectomy of colon adenomatous polyp cases as well as 
the colon adenocarcinoma cases at the Anatomic Pathology Laboratory of the Faculty of Medicine, Unika Atma Jaya/ Atma Jaya Hospital Jakarta for the period of 5 years (20102014).

\section{Materials and methods}

This study used cross-sectional analysis design with consecutive sampling. Data were taken from medical record of all patients undergoing biopsy/colectomy and based on the histopathologic evidence, diagnosed with colon adenomatous polyp or colon adenocarcinoma in Anatomic Pathology Laboratory of Faculty of Medicine UNIKA Atma Jaya/Atma Jaya Hospital Jakarta for 5 year period (2010-2014). Review of paraffin blocks and slides were done to ensure availability and sample correctness as well as to evaluate diagnosis accuracy, grades of dysplasia and differentiation. Additional immunohistochemical examination were done to detect the presence JCV T-Ag expression using the anti-SV40 T-Ag monoclonal antibody. Result is positive if nucleus of tumour mass turn brownish. Data analysis is done using Fisher's Exact Test on SPSS 19.

\section{Immunohistochemical Assay}

Immunohistochemical staining in this study is done as follows, paraffin blocks were sectioned, dewaxed with xylene (2 station, 5 minutes each), rehydrated with gradient alcohol (absolute, 96\%, 80\% and 70\%), and then treated with hydrogen peroxide (blocking) for 5 minutes, rinse with water. Heated until $110^{\circ} \mathrm{C}$ for 15 minutes in decloaking chamber (Diva), left to cool. Washed with PBS for 3 minutes, blocking was resumed with sniper for 15 minutes, then primary antibody were added, left to sit for 30 minutes. Stained with universal link for 15 minutes, TrekAvidin-HRP for 15 minutes. Then, DAB + substrate buffer was used for 2-5 minutes. Washed with running water for 5 minutes, stained with hematoxylin for 1-2 minutes, then rinsed with running water again for 5 minutes. Slides were dehydrated with gradient alcohol (70\%, 80\%, $90 \%$, absolute), clarified with xylene, sealed with entellan and cover glass. Positive control used paraffin blocks of non-Hodgkin's lymphoma, whereas negative controls used colon adenocarcinoma biopsy/colectomy tissue without antibody administration.

\section{Results}

In Table 1, from 7 samples of colon adenomatous polyp cases, 1 sample (14\%) gave positive expression results on T-Ag JCV. The samples were from the mild dysplasia cases. Similarly, in Table 2, from 16 samples of colon adenocarcinoma cases, 2 samples (12.5\%) gave positive expression results to T-Ag JCV. Both of the cases were from the low grade variety. Meanwhile the expression of of JCV T-Ag (+) and JCV T-Ag (-) in each groups are shown in Figure 1 and 2.

Table 1. Frequency distribution and percentage of colon adenomatous polyp with mild and severe dysplasia to JCV T-Ag expression.

\begin{tabular}{lccc}
\hline \multicolumn{1}{c}{ Colon Adenomatous Polyp } & JCV + & JCV - & n \\
\hline Mild Dysplasia & $1(14 \%)$ & $3(43 \%)$ & $4(57 \%)$ \\
Severe Dysplasia & $0(0 \%)$ & $3(43 \%)$ & $3(43 \%)$ \\
$\mathrm{n}$ & $1(14 \%)$ & $6(86 \%)$ & $7(100 \%)$ \\
\hline
\end{tabular}

Table 2. Frequency distribution and percentage of low and high grade colon adenocarcinoma to JCV T-Ag expression.

\begin{tabular}{lccc}
\hline \multicolumn{1}{c}{ Colon Adenocarcinoma } & JCV + & JCV - & n \\
\hline Low Grade & $2(12.5 \%)$ & $12(75 \%)$ & $14(87.5 \%)$ \\
High Grade & $0(0 \%)$ & $2(12.5 \%)$ & $2(12.5 \%)$ \\
$\mathrm{n}$ & $2(12.5 \%)$ & $14(87.5 \%)$ & $16(100 \%)$ \\
\hline
\end{tabular}



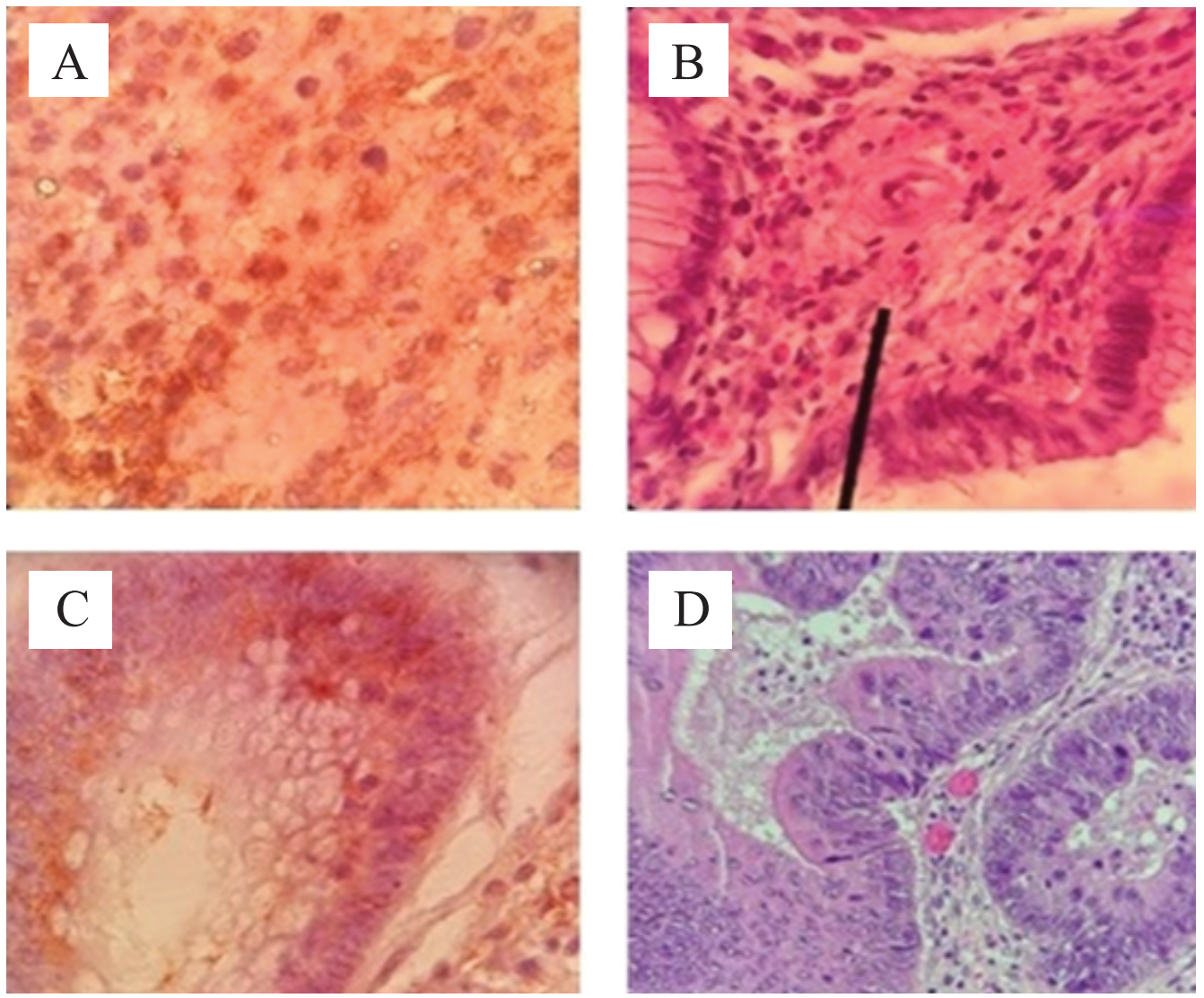

Figure 1. A: Expression of JCV T-Ag (+) on positive control (non-Hodgkin's lymphoma), 1000x magnification; B: Expression of JCV T-Ag (-) on negative control, 1000x magnification; C: Expression of JCV T-Ag (+) on colon adenoma polyp, 1000x magnification; D: Expression of JCV T-Ag (-) on colon adenomatous polyp, 400x magnification.

\section{Discussion}

This results suggests that JCV T-Ag can be found at different levels of dysplasia or differentiation, from precancerous lesions to colorectal malignancies. Statistical analysis reveals there is no significant difference in JCV $\mathrm{T}-\mathrm{Ag}$ expression between mild degree dysplasia and severe degree dysplasia of colon adenomatous polyp. Similarly, there was no significant difference in JCV T-Ag expression between low and high grade colon adenocarcinoma. It is possible that JCV T-Ag expression is carried over from early stages such as mild dysplasia colon adenomatous polyp up until later stages such as high grade colon adenocarcinoma. This explains why JCV T-Ag expression can be found in varying degrees of dysplasia or differentiation and is carried on to more advanced stages. Similar results was also reported by Woon Tae Jung, et al. ${ }^{17}$ From 74 samples of colon adenomatous polyp cases, there were 12 samples
(16\%) consisting of 1 case with severe dysplasia and 11 mild dysplasia cases, which showed positive results for JCV T-Ag expression. This study also reported that there is no significant difference in JCV T-Ag expression between mild dysplasia and severe dysplasia. This study also states that JCV T-Ag is present in the early stage of colonic carcinogenesis. A similar study by Hori, et al., stated that of 21 colon adenomatous polyp cases there were $1(4.8 \%)$ and from 23 cases of colorectal cancer, $6(26.1 \%)$ were JCV T-Ag positive. ${ }^{10}$ Lin, et al., also found that there is no significant association between the degree of colon adenocarcinoma differentiation and JCV T-Ag expression. ${ }^{16}$ This explain that carcinogenesis in colon cancer is influenced by many other factors besides JCV, such as age, race, genetics and lifestyle. In addition, JCV subtype and epidemiologic differences will also influence the difference in expression results. ${ }^{18}$ 

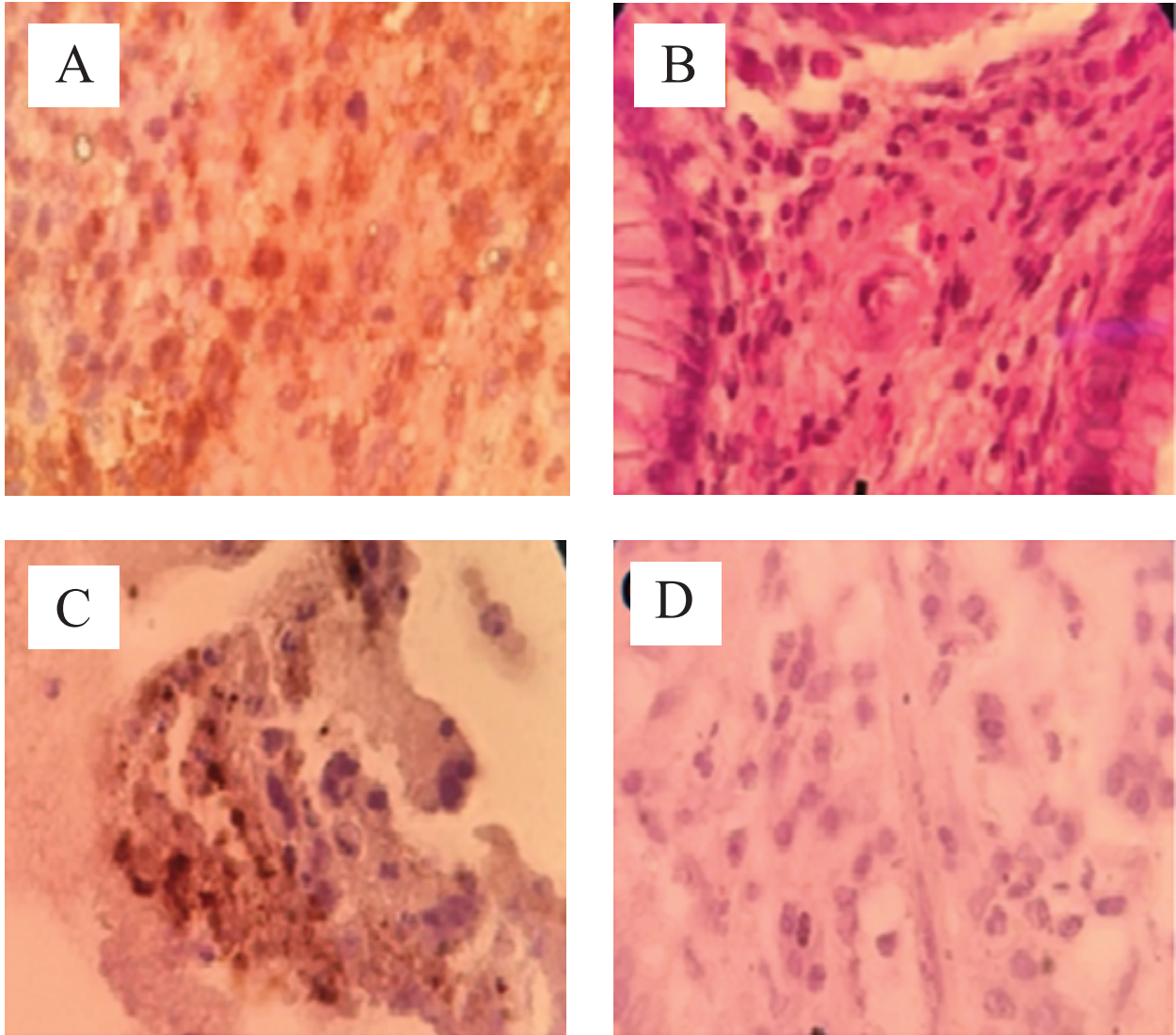

Figure 2. A: Expression of JCV T-Ag (+) on positive control (non-Hodgkin's lymphoma), 1000x magnification; B: Expression of JCV T-Ag (-) on negative control, 1000x magnification; C: Expression of JCV T-Ag (+) on colon adenocarcinoma, 1000x magnification; D: Expression of JCV T-Ag (-) on colon adenocarcinoma, 1000x magnification.

\section{Conclusion}

There was no difference in JCV T-Ag expression between mild and severe dysplasia in colon adenomatous polyp. There is also no significant difference between low and high grade colon adenocarcinoma regarding JCV T-Ag expression at the Anatomic Pathology Laboratory of Faculty of Medicine UNIKA Atma Jaya in 2010-2014.

\section{References}

1. Turner JR, Lingen MW. Oral cavity and gastrointestinal tract. In: Kumar V, Abbas AK, Aster JC, editors. Robbins Basic Pathology. 9th ed. Philadelphia: Elsevier; 2013. p.551-602.

2 World Health Organization [Internet]. GLOBOCAN 2012: Estimated Cancer Incidence, Mortality and Prevalence Worldwide in 2012 [cited 2014 Mar 24]. Available from: http://globocan.iarc.fr/Pages/ fact_sheets_population.aspx.

3 Patient [Internet]. Colorectal Cancer [cited 2014 Oct 25]. Available from: http://www.patient.co.uk/doctor/colorectal-cancer.
4. Mou X, Chen L, Liu F, Lin J, Diao P, Wang H, et al. Prevalence of JC Virus in Chinese Patients with Colorectal Cancer. PLoS One. 2012; 7(5): 0035900. doi: 10.1371/journal.pone.0035900.

5. Murray PR, Rosenthal KS, Pfaller MA. Medical Microbiology. 7th ed. Philadelphia: Elsevier; 2013.

6. Coelho TR, Almeida L, Lazo PA. JC Virus in the Pathogenesis of Colorectal Cancer, Anetiological Agent or Another Component in Multistep Process? Virol J. 2010; 7(1): 42. doi: 10.1186/1743422X-7-42.

7. Matalka I, Swedan S, Khabaz MN, Barahmeh M. JC Virus in Colorectal Cancer: Where Do We Stand? Future Virol. 2013; 8(6): 607-15.

8. Hartman AN, Newcomb PA, Potter JD. Infectious Agents and Colorectal Cancer: A Review of Helicobacter pylori, Streptococcus bovis, JC Virus, and Human papillomavirus. Cancer Epidemiol Biomarkers Prev. 2008; 17(11): 2970-9.

9. Khalili K, White MK. Human Demyelinating Disease and the Polyomavirus JC Virus. Mult Scler. 2006; 12(2): 133-42.

10. Hori R, Murai Y, Tsunenaya K, Abdel-aziz HO, Nomoto K, Takahashi $\mathrm{H}$, et al. Detection of JC Virus DNA Sequences in Colorectal Cancer in Japan. Virchow Arch. 2005; 447(4): 723-30.

11. Darbinyan A, Siddiqui KM, Slonina D, Darbinian N, Amini S, Whitw MK, et al. Role of JC Virus Agnoprotein in DNA Repair. J Virol. 2004; 78(16): 8593-600. 
12. Khalili K, Valle LD, Otte J, Weaver M, Gordon J. Human Neurotropic polyomavirus, JC Virus, and Its Role in Carcinogenesis. Oncogene. 2003; 22(33): 5181-91.

13. Caracciolo V, Reiss K, Khalili K, De Falco G, Giordano A. Role of the Interaction between large $\mathrm{T}$ Antigen and $\mathrm{Rb}$ Family Members in the Oncogenicity of JC Virus. Oncogene. 2006; 25(38): 5294-301.

14. Reiss K, Khalili K. Viruses and Cancer: Lessons from the Human Polyomavirus, JC Virus.Oncogene. 2003; 22(42): 6517-23.

15. Gan DD, Khalili K. Interaction between JC virus large T-antigen and B-catenin. Oncogene. 2004; 23(2): 483-90.
16. Lin PY, Fung CY, Chang FP, Huang WS, Chen WC, Wang JY, et al. Prevalence and Genotype Identification of Human JC Virus in Colon Cancer in Taiwan. J Med Virol. 2008; 80(10): 1828-34.

17. Jung WT, Li MS, Goel A, Boland CR. JC Virus T-antigen Expression in Sporadic Adenomatous Polyps of the Colon. Cancer. 2008; 112(5): 1028-36.

18. Cayres-Vallinoto IMV, Vallinoto ACR, Azevedo VN, Machado LFA, Ishak M de OG, Ishak R. Human JC Virus Infections as A Bioanthropological Marker of the Formation of Brazilian Amazonian Population. PloS One. 2012; 7(10): e46523. doi: 10.1371/journal. pone.0046523. 